The Bangladesh Veterinarian (2013) 30(1) : 20 - 24

\title{
Effects of probiotics on haematology and biochemical parameters in mice
}

\author{
M Salahuddin, H Akhter, S Akter, MA Miah* and N Ahmad \\ Department of Physiology, Faculty of Veterinary Science, Bangladesh Agricultural \\ University, Mymensingh-2202, Bangladesh
}

\begin{abstract}
Probiotic organisms are live microorganisms thought to be beneficial to the host. To know the effect of probiotic supplemented food on haemato-biochemical parameters in mice, a total of 20 two-month-old Swiss Albino mice were randomly divided into four equal groups. Group A was control, fed commercial mouse pellets, and others were treated with $5 \mathrm{~g}$ (group B), $10 \mathrm{~g}$ (group C) and $20 \mathrm{~g}$ (group D) probiotics (curd), respectively, in mouse pellets for 45 days. Total erythrocyte count and haemoglobin concentration were significantly $(\mathrm{P}<0.01)$ higher in treated group than in controls. Total serum cholesterol, triglyceride, high density lipoprotein and low density lipoprotein values decreased significantly $(\mathrm{P}<0.01)$ in treated groups. Serum uric acid value was significantly higher $(\mathrm{P}<0.01)$ in treated groups. It is suggested that probiotics help improve haematology and lipid profile but not kidney function. (Bangl. vet. 2013. Vol. 30, No. 1, 20 - 24)
\end{abstract}

\section{Introduction}

Probiotics are bacteria, fungi or yeasts that have favourable effects on hosts by improving the characteristics of intestinal microflora (Fuller, 1989). Probiotics can be classified into colonizing species (Lactobacillus sp., Enterococcus sp. and Streptococcus sp.) and free, non-colonizing species (Bacillus and Saccharomyces cerevisiae). Probiotics display several ways of action: antagonistic action towards pathogenic bacteria by secretion of products that inhibit their development, such as bacteriocins, organic acids and hydrogen peroxide; or competition for locations to adhere to the intestinal mucous membranes; or competition for nutrients (Patterson and Brukholder, 2003). They reduce the risk of disease (Line et al., 1998; Mountzouris et al., 2007), improve the function of the immune system (Zulkifli et al., 2000; Hossain et al., 2005) and influence morphology and function of intestines (Uscebrka et al., 2005; Yang et al., 2009). In mice, probiotics, especially Streptococcus thermophilus, increase body weight by enhancing digestion and absorption, and inhibit the synthesis of cholesterol, so that cholesterol levels drop and prevent atherosclerosis and coronary heart disease (Sanders, 2000).

Probiotics can be included in pellets, capsules, paste, powder, curd or granules, which can be given to animals directly or through food. Nearly all probiotics currently on the market contain lactobacilli and/or streptococci, few contain bifid bacteria. Curd

\footnotetext{
*Corresponding author:- E-mail: alam.dina@gmail.com
} 
contains live viable strains of naturally occurring beneficial microorganisms. There is no comprehensive precise reports are available on the effects of probiotics on blood and biochemical parameters. This study was undertaken to investigate the effect of dietary supplementation of probiotics (curd) on total erythrocyte count (TEC), haemoglobin $(\mathrm{Hb})$ total cholesterol, triglyceride, high-density lipoprotein (HDL) lowdensity lipoprotein (LDL) and uric acid in the mice.

\section{Materials and Methods}

Animals

Twenty male Swiss Albino mice (Mus musculus) of six to eight weeks old, with an average body weight of $18-22 \mathrm{~g}$ were obtained from International Centre for Diarrhoeal Diseases Research Bangladesh (ICDDR'B), Dhaka, Bangladesh. Standard mouse pellets were obtained from ICDDR'B. Before being used mice were allowed free access to a basal diet of mouse pellets and water for three days for acclimatization.

\section{Experimental protocol and diets}

Curd probiotic containing live viable strains of naturally occurring beneficial microorganisms was used. The mice were randomly divided into four equal groups. Group A was considered as control, fed on standard mouse pellet (5g/mouse/day) and drinking water and others were supplemented with $5 \mathrm{~g}$ curd (group B), $10 \mathrm{~g}$ curd (group C), 20g curd (group D) per 25g of standard mouse pellet, respectively, for 45 days.

\section{Collection of blood for haematology}

After completion of experimental period, blood samples were collected by sacrificing the mice. The mice were kept fasting overnight, then placed in an airtight container one by one containing cotton soaked in chloroform. They were checked for unconsciousness. The abdominal and thoracic cavities were opened and the blood was collected by a syringe directly from the heart. A portion of blood was then taken in a test tube containing 3.8\% sodium citrate solution. The remaining blood was used for the collection of serum. Total erythrocyte count (TEC) and haemoglobin content $(\mathrm{Hb})$ were determined as described by Shastry (1983).

\section{Preparation of serum for biochemical analysis}

About $2 \mathrm{ml}$ of blood was collected in sterile glass test tubes, which were placed in slanting position at room temperature for six hours. The tubes were kept overnight at $4^{\circ} \mathrm{C}$. Serum was separated and centrifuged to remove unwanted blood cells where necessary. The samples were stored at $-20^{\circ} \mathrm{C}$. Serum lipid profile was assayed by conventional enzymatic methods on a Hitachi 911 automated analyzer from Roche Diagnostics (Laval, QC, Canada) according to the manufacturer's specifications. 


\section{Statistical analysis}

The data were analysed statistically between normal and treated values by one way ANOVA with post-hoc Duncan's multiple range test.

\section{Results and Discussion}

\section{Haematology}

Total erythrocyte count and haemoglobin concentration increased in a dosedependent manner (Table 1). The highest values were recorded in group $\mathrm{D}$, which were significantly higher $(\mathrm{P}<0.05)$ than control group $\mathrm{A}$. These findings are consistent with those of Islam et al. (2004); Hossain et al. (2005); Awad et al. (2009)

Table 1. Effects of varying concentration of probiotics on haematological parameters (Mean \pm SE) of mice

\begin{tabular}{l|c|c|c|c}
\hline \multicolumn{1}{c|}{ Haematological parameters } & \multicolumn{4}{c}{ Mean \pm SE } \\
\cline { 2 - 5 } & Group-A & Group-B & Group-C & Group-D \\
\hline Total erythrocyte count (million/mm3) & $6.3 \pm 0.4$ & $6.4 \pm 0.1$ & $7.7 \pm 0.1$ & $10.0 \pm 0.1^{*}$ \\
Haemoglobin (g\%) & $8.6 \pm 0.1$ & $9.2 \pm 0.1$ & $10.4 \pm 0.1$ & $11.7 \pm 0.1^{*}$ \\
\hline
\end{tabular}

* indicates significant $(\mathrm{P}<0.05)$ (group A versus group D)

\section{Effects on biochemical parameters}

The effect of probiotics on serum cholesterol, triglyceride, HDL, LDL and uric acid concentration is presented in Table 2. The control mice had the highest total cholesterol and triglyceride. A dose-dependent decrease in total cholesterol and triglyceride occurred in all treated groups. The values in groups $\mathrm{C}$ and $\mathrm{D}$ were significantly lower $(\mathrm{P}<0.01)$ than in control $\mathrm{A}$. The present value of cholesterol and tryglycerides in mice are consistent with the findings of Homayouni et al. (2012) in man and animal, Mustari and Ahmad (2011) in rat, Ooi and Liong (2010); Shareef and Al-Dabbagh (2009) in man who reported that probiotic factors inhibit synthesis of cholesterol and total triglyceride in man.

Table 2. Effects of probiotics on biochemical parameters (Mean \pm SE) of blood of mice

\begin{tabular}{l|c|c|c|c}
\hline \multirow{2}{*}{ Biochemical parameters } & \multicolumn{4}{|c}{ Mean \pm SE } \\
\cline { 2 - 5 } & Group-A & Group-B & Group-C & Group-D \\
\hline Cholesterol (mg/dL) & $108.9 \pm 2.0$ & $100.4 \pm 0.2$ & $95.0 \pm 0.4^{* *}$ & $90.7 \pm 0.5^{* *}$ \\
Triglyceride (mg/dL) & $58.5 \pm 0.5$ & $53.0 \pm 0.4$ & $48.0 \pm 0.4^{* *}$ & $43.0 \pm 0.7^{* *}$ \\
HDL (mg/dL) & $44.4 \pm 0.4$ & $41.6 \pm 0.3$ & $38.7 \pm 0.3^{* *}$ & $35.7 \pm 0.5^{* *}$ \\
LDL (mg/dL) & $59.2 \pm 0.5$ & $51.0 \pm 0.4^{*}$ & $40.6 \pm 0.3^{* *}$ & $31.0 \pm 0.4^{* *}$ \\
Uric acid (mg/dL) & $4.3 \pm 0.1$ & $5.6 \pm 0.1$ & $7.0 \pm 0.1^{* *}$ & $7.5 \pm 0.1^{* *}$ \\
\hline
\end{tabular}

${ }^{*} \mathrm{P}<0.05$, ${ }^{* *} \mathrm{P}<0.01$ 
Similarly, HDL concentration was highest in control group and there was a dosedependent decrease in groups $\mathrm{B}, \mathrm{C}$ and $\mathrm{D}$ (Table 2). LDL values were also significantly lower $(\mathrm{P}<0.01)$ in groups $\mathrm{B}, \mathrm{C}$ and $\mathrm{D}$ than in control group $\mathrm{A}$. The present findings of LDL cholesterol, but not HDL, are consistent with the findings of Homayouni et al. (2012); Guo Z et al. (2011); Ooi and Liong (2010) who reported that a diet rich in probiotics decreases total cholesterol and LDL cholesterol concentration in blood plasma of man but the findings differ from Joy (1997) who stated that probiotic did not influence total LDL. We found HDL and cholesterol values are inconsistent with that of previous findings. This may be due to use of different strain of probiotics in curd or different experimental condition, time and duration of study. It needs to be confirmed by several studies.

Serum uric acid usually reflects the functions of kidney. We found uric acid concentration was increased significantly $(\mathrm{P}<0.01)$ among the probiotic treated groups $\mathrm{C}$ and $\mathrm{D}$ than the control group A. Meanwhile, there were no gross abnormalities found in kidneys of probiotics treated mice that may be due to increased serum uric acid level was at tolerance level. The result of the current study is obscure and it needs to be clarified by other studies. The uric acid concentration of present work consistent to those of Sultan and Abdul- Rahman (2011); Hamid and Qureshi (2009); Swain and Johri (2000) who detected an increased uric acid level in serum with the increase level of probiotics in broilers.

\section{Conclusions}

It is concluded that the feeding of commercial ration with different level of probiotic improved TEC and $\mathrm{Hb}$ concentrations and decreased serum cholesterol, TG, HDL and LDL. Uric acid values were higher in treated groups B, C and D than in the control group A. Our current findings suggested and strengthened the previous findings that probiotics supplementation helps in improving normal hematology and lipid profile. Molecular mechanism of hypolipidemic effect of probiotics needs to be evaluated by advanced studies

\section{References}

Awad WA, Ghareeb K, Abdel-Rahheem S, Bohm J 2009: Effects of dietary inclusion of probiotic and symbiotic on growth performance, organ weights, and intestinal histomorphology of broiler chickens. Poultry Science 88 49-56.

Fuller R 1989: Probiotics in man and animals. The Journal of Applied Bacteriology 66 365-78.

Guo Z, Liu XM, Zhang QX, Shen Z, Tian FW, Zhang H, Sun ZH, Zhang HP, Chen W 2011: Influence of consumption of probiotics on the plasma lipid profile: a meta-analysis of randomized controlled trials. Nutrition, Metabalism and Cardiovascular Diseases 21 $844-850$.

Hamid MS, Qureshi A 2009: Trial study on the efficacy of protexin (water-soluble) on the performance of broilers. Pakistan Veterinary Journal 21224 - 225. 
Homayouni A, Payahoo L, Azizi A 2012: Effects of probiotics on lipid profile: A review. American Journal Food Technology 7 251-265.

Hossain MA, Ali MA, Chowdhury SD, Haque MA, Kabir SML 2005: Effect of yoghurt and protexin boost on gut microflora and broiler performance. The Agriculturists 3 24-29.

Islam MW, Rahamn MM, Kabir SML, Kamruzzaman SM and Islam MN 2004: Effects of probiotics supplementation on growth performance and certain haemato-chemical parameters in broiler chickens. Bangladesh Journal of Veterinary Medicine 2 39-43.

Joy AD, Samuel JJ 1997: Effect of probiotic supplementation on the performance of broilers. Journal of Veterinary and Animal Sciences 28 10-14.

Ooi LG, Liong MT 2010: Cholesterol-lowering effects of probiotics and prebiotics: a review of in vivo and in vitro findings. International Journal of Molecular Science $\mathbf{1 1}$ 2499-2522.

Line EJ, Bailey SJ, Cox NA, Stern NJ, Tompkins T 1998: Effect of yeast-supplemented feed on Salmonella and Campylobacter populations in broilers. Poultry Science 77 405-410.

Mountzouris KC, Tsirtsikos P, Kalamara E, Nitsch S, Schatzmayr G, Fegeros K 2007: Evaluation of the Efficacy of a Probiotic Containing Lactobacillus, Bifidobacterium, Enterococcus, and Pediococcus Strains in Promoting Broiler Performance and Modulating CecalMicroflora Composition and Metabolic Activities. Poultry Science 86 309-317.

Mustari A, Ahmad N 2011: Effects of probiotics on serum biochemical parameter in rats. The Bangladesh Veterinarian 28 70-74.

Patterson JA, Burkholder MK 2003: Application of prebiotics and probiotics in poultry production. Poultry Science 82 627-631.

Sanders ME 2000: Considerations for use of probiotic bacteria to modulate human health. The Journal of Nutrition 130 384S-390S.

Shareef AM and Al-Dabbagh ASA 2009: Effect of probiotic (Saccharomyces cervisiae) on performance of broiler chicks. Iraqi Journal of Veterinary Science 23 23-29.

Shastry GA 1983: Veterinary Clinical Pathology. 2ndedn., CBS Publishers and Distributors, Delhi, India.

Sultan KH and Abdul- Rahman SY 2011: Effect of probiotic on some physiological parameters in broiler breeders. International Journal of Poultry Science 10 626-628.

Swain and Johri 2000: Effects of probiotic (Saccharomyces cerevisiae) on growth performance and haemato-biochemical parameters of broiler chicks. International Journal of Poultry Science 2 142-148.

Uscebrka G, Zikic D, Peric L, Jurcoane S, Milosevic N 2005: Effect of probiotic supplementation on the small intestinum morphology of broiler chickens. Proceedings: $34^{\text {th }}$ International session of scientific communications of the faculty of animal science, Bucharest, Romania pp. 67-71.

Yang Y, Iji PA, Choct M 2009: Dietary modulation of gut microflora in broiler chickens: a review of the role of six kinds of alternatives to in-feed antibiotics. World's Poultry Science Journal 65 97-114.

Zulkifli I, Abdullah N, Azrin NM, Ho YW 2000: Growth performance and immune response of two commercial broiler strains fed diets containing Lactobacillus cultures and oxytetracycline under heat stress conditions. British Poultry Science 41 593-597. 